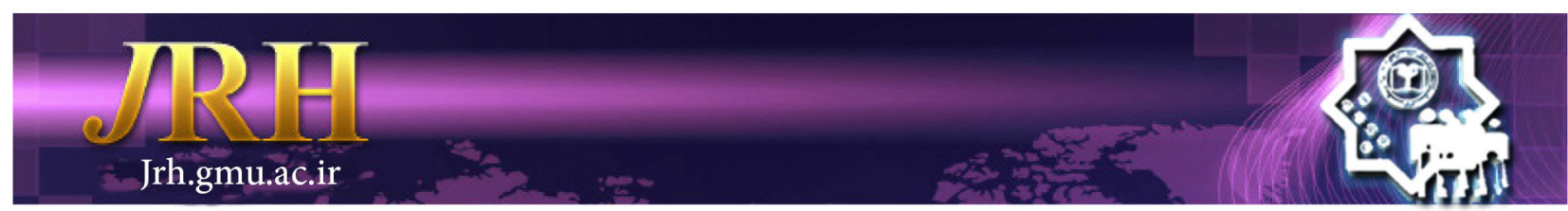

\title{
Role of maternal parenting styles in predicting oppositional defiant, behavior, conduct, mood, and separation anxiety disorders among students
}

Mehdi Rostami ${ }^{1}$, Nadereh Saadati ${ }^{2}$

\author{
Journal of Research \& Health \\ Social Development \& Health Promotion \\ Research Center \\ Vol. 8, No.5, Sep \& Oct 2018 \\ Pages: 418- 424 \\ DOI: $10.29252 /$ jrh.8.5.418 \\ Original Article
}

1. Correspondence to: Department of Educational and Counseling, Faculty of Literature, Humanities and Social Sciences, Science and Research Branch, Islamic Azad University, Tehran, Iran

Email: Mehdi.rostami25@gmail.com

2. Department of General Psychology, Faculty of Educational Sciences \& Psychology, Islamic Azad University Isfahan (Khorasgan) Branch, Isfahan, Iran

Received: 18 Apr 2015

Accepted: 24 Sep 2015

How to cite this article: Rostami M, Saadati N. Role of maternal parenting styles in predicting oppositional defiant disorders of behavior, manner, disorders mood and separation anxiety among elementary school students. J Research \& Health2018; 8(5): 418- 424 .

\begin{abstract}
The way the parents build their relationships with their children is the strongest factor affecting family interaction patterns. This study aimed to examine the role of maternal parenting styles in predicting oppositional defiant, behavior, conduct, mood, and separation anxiety disorders among elementary school students. In this research, 86 children among all those referring to the counseling center of the 5th educational region in Tehran were conveniently selected and their mothers were asked to answer Bamrind parenting styles and pathological symptoms CSI-4 (parental form) questionnaires. Correlation and multiple regressions were used for data analysis. The results showed that there was a significantly negative relationship between behavioral and mood disorders and the authoritarian parenting style, as well as between antagonism disorder, oppositional defiant disorder, and separation anxiety and permissive parenting style. The authoritarian parenting style could predict the behavioral and mood disorders and the permissive parenting style could predict antagonism disorder, oppositional defiant disorder, and separation anxiety.
\end{abstract}

Keywords: Anxiety, Behavioral, Disorder, Mood, Parenting

\section{Introduction}

The way the parents build their relationships with their children is the strongest factor affecting family interaction patterns, especially during the life periods in which children have basic mental development changes [1]. Parents who are weak and unstable and lack confidence in their communications would not reach an agreement in their training styles. They use parenting patterns including banishing, enormous protection with toleration or domination, double-disciplinary, moral standards' laxity, unreasonable perfection-seeking and emotional instability. These will lead to stabilize neurotic behaviors in children and cause children to be more needful emotionally and affectively and in this situation, they will be disappointed in the sense of trust and security that is the basis for emotional development [2].

Families employ different parenting styles in bringing up their children. Parenting styles convey relatively stable methods and patterns used by the parents for communicating with family members and make a mutual influence and impressive flow [3]. Bamrind in 1991 introduced parenting style as an output of parent's control and divided it into authoritarian, authoritative, and permissive categories concerning the behavioral dimensions of warmth and control. The authoritarian parenting style is specified with strict control, high-level limitation, unstable and harsh discipline, low levels of emotional support 
and warmth [4]. Study results have shown that parents with the authoritarian parenting style use punitive approaches including threats, criticism, and rule dictating in a compulsory way and restrict the children's self-observing and decide on the suitable and appropriate behaviors for their children [5].

Authoritative parenting style is specified by a combination of control and high-level emotional support, the appropriate level of independence, and bilateral relations between parents and children. Parents using this method are described as friendly and warm people. Yet, they have their control over their children's behaviors; they have reasonable explanations and causes for their demands and define clear rules to the children for behaving appropriately. This parenting method is associated with positive consequences like a high-level academic achievement, greater selfconfidence, and better relationships with the peers [6]. Permissive parenting style is characterized by the lack of parents' control and responding to the child's desire. Permissive parents try to prepare a warm, relaxed, and respectful environment to their children but they do not have control and supervision of their children's acts. Parents using the permissive parenting style apply unstable or unstructured rules. Although these are parents of noble sentiments, their regulationconducting failure will lead to children's low self-esteem because their children also fail to learn appropriate forms of self-regulation [7]. Authoritarian parenting is associated with negative behavioral outcomes such as aggressive, external, and internal disorders and lower emotional functioning [4]. Such children are not disposed toward partnership and suffer from low self-esteem, depression, and decisionmaking problems in adulthood [8]. These children are obedient and follower, having low academic achievement and self-perception, and high mental and physical disorders [9]. Studies conducted on pre-elementary schoolchildren have shown that there are many authoritarian parenting beliefs. High maternal negativism and dispirit parent-child relationship in families with children having behavioral problems and maternal strict discipline may lead to increased negative emotional and low sociability in the children [10].

Authoritative parenting style has a negative relationship with antisocial behaviors. The children of these parents are in desirable conditions from the emotional-social and educational outcomes' point of view; they have high self-esteem and tend to have high self-biased, self-control, and curiosity [11]. These children have high levels of competence, academic achievement, social development, and self-cognitive and lower behavioral and psychological problems compared to peers exposed to other styles [8]. Permissive parenting style is associated with children's delinquency and aggression and poor academic development, high crime and low psychological functioning due to the lack of parents' supervision. These children have low social skills and self-esteem and are often selfish, dependent, and antisocial [6]. Child psychologists and experts have found that parenting style is the reason for many children's abnormalities and emphasized on the impact of childhood events on forming personality and their future lives. According to the fact that there would be no change in children's mental condition without changing the family functioning, the complex and bilateral relationship between behavioral problems and family's variables must be taken into consideration in order to improve the child behavior; therefore, this study aimed to investigate the role of maternal parenting styles in predicting oppositional defiant disorder, behavior or conduct disorder, mood disorders, and separation anxiety in 7-12-year-old elementary students referring to the counseling center of the 5 th educational region in Tehran.

\section{Method}

This research is a cross-sectional study, which was performed during the school year of 2014-15 by the counseling center of the 5 th educational region in Tehran, among male and female elementary-school students aged between 7 and 12. A convenience sample of 86 participants was achieved consisting of students 
with diagnosed behavioral problems reported in their files; afterward, their mothers were called to participate in the study. After making sure of confidentiality of the research information, they took surveys regarding the methods of nurturing children and children symptom inventory (CSI). For statistical analysis, the correlation coefficient and multiple regressions in SPSS- 19 were applied. P-value $<0.05$ was considered for significance level.

Parenting style questionnaire (Baumrind): The original form of the questionnaire consists of 30 items designed by Baumrind [12] and translated by Hosseinpoor [13]. The questionnaire measures the parenting style in three dimensions. There are five columns in front of each item (completely agree, partly agree, partly disagree, disagree, completely disagree), which are scored 0-4, respectively. Burai in 1991 used the test-retest method for calculating the reliability and the obtained results are as follows: Permissive style 0.81 , authoritarian style 0.86 , and authoritative style 0.78 ; he also examined the internal consistency using Cronbach's alpha formula and obtained the coefficient of 0.75 for permissive style, 0.85 for authoritarian style, and 0.82 for authoritative style [14].

Child Symptom Inventory (CSI-4), parents' form: Child Symptom Inventory (CSI-4) is a behavior scale rating for screening behavioral and emotional disorders in 5-12-year-old children and has two forms for parents and teachers. In this research, the parents' checklist was used which consists of 110 questions. Every mentioned item was answered in a four-point scale: never, sometimes, often, and oftentimes.
The symbolic signs (small and large circles) were used for parents' better understanding. Three groups of disorders were being focused in this research and among all the examined groups, group B, G, and $\mathrm{J}$ were used with a total of 23 questions which measured three kinds of disorders; oppositional defiant disorder (questions 19-26), behavior or conduct disorder (question 27-41), mood disorder (question 60 or D45 or 61, 62-64, 6770 ), and separation anxiety disorder (question 88-95). The symptom severity scoring method was used in this study. The never, rarely, sometimes, and oftentimes options were scored $0,1,2$, and 3, respectively; the symptom severity score was obtained by summing the items scores. In Grayson and Carlson research in 1991 on CSI-3R, the sensitivity for the oppositional defiant disorder, conduct disorder, and attention-deficit and hyperactivity disorder was reported as 0.93 , 0.93 , and 0.77, respectively [15]. In Kalantari et al. study, the questionnaire's validity was 0.91 for the teachers' form and 0.85 for the parents' form using the bisection method [16]. For statistical analysis, the correlation coefficient and multiple regressions in SPSS19 were applied.

\section{Results}

The scores of the variables of parenting styles, oppositional defiant disorder, behavior or conduct disorder, mood disorders, and separation anxiety are reported in Table 2 . In Table 3, the correlation matrix and in Table 4, the multiple regressions are reported.

Table 1 Demographic characteristics of the study samples $(N=86)$

\begin{tabular}{llcc}
\hline Group & Levels & Frequency & Percentage \\
\hline \multirow{3}{*}{ Mothers' Age } & $20-25$ & 8 & $9 \%$ \\
& $26-30$ & 36 & $42 \%$ \\
& $31-35$ & 42 & $49 \%$ \\
& Total & 86 & $100 \%$ \\
\hline \multirow{4}{*}{ Mothers' Education } & Diploma & 28 & $33 \%$ \\
& Bachelor Degree & 43 & $50 \%$ \\
& Master of Science & 15 & $17 \%$ \\
Children Age & Total & 86 & $100 \%$ \\
& $7-9$ & 39 & $45 \%$ \\
& $10-12$ & 47 & $55 \%$ \\
& Total & 86 & $100 \%$ \\
\hline
\end{tabular}


Table 2 Descriptive indicators for parenting styles oppositional defiant disorder, behavior or conduct disorder, mood disorders, and separation anxiety in students $(n=86)$

\begin{tabular}{lcccc}
\hline Variable & Min & Max & mean & Standard Deviation \\
\hline Permissive parenting style & 5 & 33 & 21.55 & 7.45 \\
Authoritarian parenting style & 14 & 40 & 24.93 & 6.58 \\
Authoritative parenting style & 5 & 39 & 17.63 & 5.98 \\
Oppositional defiant disorder & 0 & 13 & 5.65 & 3.29 \\
Behavior or conduct disorder & 0 & 22 & 4.36 & 4.35 \\
Mood disorder & 0 & 15 & 4.37 & 3.60 \\
Separation anxiety disorder & 0 & 15 & 5.20 & 3.52
\end{tabular}

Table 3 Correlation matrix for parenting styles and oppositional defiant disorder, behavior or conduct disorder, mood disorders, and separation anxiety in students $(n=86)$

\begin{tabular}{clccccccc}
\hline & Variables & 1 & 2 & 3 & 4 & 5 & 6 & 7 \\
\hline 1 & Permissive parenting style & 1 & & & & & & \\
2 & Authoritarian parenting style & .09 & 1 & & & & & \\
3 & Authoritative parenting style & $.52^{* *}$ & 03. & 1 & & & & \\
4 & Oppositional defiant disorder & $-.27^{* *}$ & -.14 & -.12 & 1 & & & \\
5 & Behavior or conduct disorder & .10 & $-.26^{*}$ & .10 & 39. & 1 & & \\
6 & Mood disorder & .05 & $-.46^{* *}$ & .07 & $.23^{*}$ & $.59^{* *}$ & 1 & \\
7 & Separation anxiety disorder & $.41^{* *}$ & -.10 & .05 & $.22^{* *}$ & $.51^{* *}$ & $.41^{* *}$ & 1 \\
8 & Mean & 21.55 & 24.93 & 17.63 & 8.50 & 4.36 & 4.37 & 5.20 \\
9 & Standard Deviation & 7.45 & 6.58 & 5.98 & 2.65 & 4.35 & 3.60 & 3.52 \\
\hline$* * \mathrm{p}<0.01,{ }^{*} \mathrm{p}<0.05$ & & & & & & &
\end{tabular}

The results in Table 3 show that the behavior, conduct, and mood disorders are significantly negatively associated with authoritarian parenting style and the same relationship is found between oppositional defiant and separation anxiety disorders and permissive parenting style.

Table 4 A summary of multiple regressions coefficients in examining oppositional defiant, behavior, conduct, mood, and separation anxiety disorders in students based on the parenting styles

\begin{tabular}{|c|c|c|c|c|c|c|c|c|c|}
\hline Predictor & Proof & & $\mathrm{R}$ & $\mathrm{R}^{2}$ & $\mathrm{~F}$ & $\mathrm{~B}$ & Beta & $\mathrm{T}$ & Sig \\
\hline & - & $\begin{array}{c}\text { Fixed } \\
\text { Quantity }\end{array}$ & - & - & - & 11.59 & - & 8.32 & 0.001 \\
\hline $\begin{array}{l}\text { Permissive parenting style } \\
\text { Authoritarian parenting style } \\
\text { Authoritative parenting style }\end{array}$ & $\begin{array}{l}\text { Oppositional } \\
\text { defiant } \\
\text { disorder }\end{array}$ & & 0.29 & 0.08 & 2.65 & $\begin{array}{c}-0.09 \\
-0.04 \\
0.01 \\
\end{array}$ & $\begin{array}{c}-0.27 \\
-0.11 \\
0.02 \\
\end{array}$ & $\begin{array}{c}-2.20 \\
-1.11 \\
0.19 \\
\end{array}$ & $\begin{array}{l}0.03 \\
0.26 \\
0.84\end{array}$ \\
\hline Authoritative parenting style & - & $\begin{array}{c}\text { Fixed } \\
\text { Quantity }\end{array}$ & - & - & - & 6.78 & - & 2.96 & 0.004 \\
\hline $\begin{array}{l}\text { Permissive parenting style } \\
\text { Authoritarian parenting style } \\
\text { Authoritative parenting style }\end{array}$ & $\begin{array}{l}\text { Behavior, } \\
\text { conduct } \\
\text { disorder }\end{array}$ & & 0.26 & 0.07 & 2.80 & $\begin{array}{c}0.05 \\
-0.18 \\
0.04\end{array}$ & $\begin{array}{c}0.09 \\
-0.027 \\
0.06\end{array}$ & $\begin{array}{c}0.79 \\
-2.56 \\
0.50 \\
\end{array}$ & $\begin{array}{l}0.43 \\
0.01 \\
0.61 \\
\end{array}$ \\
\hline & - & $\begin{array}{c}\text { Fixed } \\
\text { Quantity }\end{array}$ & - & - & - & 9.56 & - & 5.49 & 0.001 \\
\hline $\begin{array}{l}\text { Permissive parenting style } \\
\text { Authoritarian parenting style } \\
\text { Authoritative parenting style }\end{array}$ & $\begin{array}{l}\text { Mood } \\
\text { disorder }\end{array}$ & & 0.48 & 0.23 & 8.19 & $\begin{array}{c}0.03 \\
-0.26 \\
0.03 \\
\end{array}$ & $\begin{array}{c}-0.06 \\
-0.46 \\
0.05 \\
\end{array}$ & $\begin{array}{c}0.56 \\
-4.48 \\
0.51 \\
\end{array}$ & $\begin{array}{c}0.57 \\
0.001 \\
0.60 \\
\end{array}$ \\
\hline & - & $\begin{array}{c}\text { Fixed } \\
\text { Quantity }\end{array}$ & - & - & - & 3.91 & - & 10.69 & 0.02 \\
\hline $\begin{array}{l}\text { Permissive parenting style } \\
\text { Authoritarian parenting style } \\
\text { Authoritative parenting style }\end{array}$ & $\begin{array}{l}\text { Separation } \\
\text { anxiety } \\
\text { disorder }\end{array}$ & & 0.48 & 0.23 & 8.31 & $\begin{array}{l}0.26 \\
-0.08 \\
-0.13\end{array}$ & $\begin{array}{l}0.55 \\
-0.14 \\
-0.22\end{array}$ & $\begin{array}{r}4.82 \\
-1.53 \\
-1.69\end{array}$ & $\begin{array}{c}0.001 \\
0.12 \\
0.06\end{array}$ \\
\hline
\end{tabular}

The results in Table 4 show that the permissive parenting style is a predictor of oppositional defiant disorder in the study sample ( $p>0.03)$; also the authoritarian parenting style is a predictor of behavior and conduct disorder $(\mathrm{p}<0.01)$ and mood disorder $(\mathrm{p}<0.01)$ and the permissive parenting style can predict the separation anxiety disorder $(\mathrm{p}<0.01)$. 


\section{Discussion}

The results showed that there is a significantly negative relationship between behavior, conduct, and mood disorders and authoritarian parenting style and between oppositional defiant and separation anxiety disorders and permissive parenting style. The present study also showed that the authoritarian parenting style is a predictor of behavior, conduct, and mood disorders and the permissive parenting style could predict the oppositional defiant and separation anxiety disorders. The obtained results suggest that those mothers who took their children to the counseling center used authoritarian and permissive parenting styles more than the authoritative parenting style. These findings are in line with the other researchers' studies such as Bamind [4], Galambos et al [10], Asher [17], Okorododo [18], and Lei-yin et al [19] abroad and Farzi Golfazani [20], Sadr-O- Sadaat et al [3], Kar Ahmadi et al [21], Kamijani and Maher [22], Sohrbi and Hassani [23], and Sadegh Khani [7] in Iran.

Recent studies have considered the relationship between care and structure components in order to explain the parenting style of the mothers who have children with oppositional defiant, behavioral, mood and separation anxiety disorders [18]. Parental responsibility and intimacy are the elements of relationship and care components and control and limitation are the structural elements. Generally, these three components are perceived in the authoritative parenting style appropriately. These parents make limitations to their children with reasonable demanding and have control and supervision over their behavior. At the same time, they show intimacy and affection in their relationships and use affectionate behavior like hugging and kissing more. They feel responsible for their children. Since they encourage their children and exhort them in family decisionmaking, their children have high self-esteem and self-regulation. The authoritative style has a positive relationship with more social relationships, reasoning, and kindness [8].

According to the researchers like Ericsson,
Piaget, and others about the cognitive, social, and emotional development in children, it seems when the parenting style is inappropriate from the care, relation, and structure points of view, the improper development field would provide and consequently cause acts labeled as negative. By increasing these components, the positive behaviors will increase as well and this condition is associated with the authoritative parenting style [4]. On the other hand, decreasing these components will decrease the positive behaviors, which are associated with the permissive and authoritarian parenting styles. In the permissive parenting style, the amount of the structure is at the lowest level. These parents do not have control over their children's behavior; so, most of these children are incompetent. The care component is also low in these parents. Therefore, it is expected that this kind of parenting method is associated with the oppositional defiant and behavioral disorders in children due to its negative consequences and up-to-dated problems [8]. The results of the authoritarian parenting style examined showed that this kind of parenting style has a high level of the structure so that strict control and hardness cause a flexible structure. The relation component is low in this style and these parents use hard punishment for controlling. This style has consequences for children including negative behaviors in the form of externalizing problems like oppositional defiant and behavioral disorders and internalized problems like depression. Over time, by affecting children with this type of parenting style, they would be distressed, lonely, depressed, and unhappy; so, their internalized problems would increase [2223]. Employment and lack of cooperation from the side of fathers restricted the study to investigate only mothers. Another restriction was the study of the parenting style of the mothers of troublesome children only. For future studies, it is suggested to compare the parenting style of these parents (mothers and fathers) and parents of normal children. 


\section{Conclusion}

As mentioned before, every parenting style has its own effects on children's behavior among which, the permissive and authoritarian styles have more negative and destructive effects. Thus, according to the findings of this study, paying more attention to the effects of parenting styles and their destructive and negative consequences is necessary. Thus, parents should be advised about these training patterns and their effects on the children. This will be possible by the arrangement of skills training programs for parenting in schools and neighborhood houses.

\section{Acknowledgments}

We would like to thank all the people who helped us in performing this research.

\section{Contributions}

Study design: MR, NS

Data collection and analysis: MR

Manuscript preparation: MR, NS

\section{Conflict of Interest}

The authors declare that they have no competing interests.

\section{Funding}

The author (s) received no financial support for the research, authorship and/or publication of this article.

\section{References}

1- Alizadeh H, Andries C. Interaction of parenting styles and attention deficit hyperactivity disorder in Iranian. Child Fam Behav Ther2002; 24(3); 37-52.

2- McCarty CA, Lau AS, Valeri SM, Weisz JR. Parentchild interachions in relation to critical and emotionally overinvolved experessed emotion: is EE a proxy for behavior? J Abnorm Child Psychol2004; 32(1): 83-93.

3- Sadrossadat S, Shams Esfandabad H, Emamipour S. Parenting and family functioning among irresponsible families, families with behavioral disorder children and normal families. Journal of Shahrekord University of Medical Sciences 2005; 7(2) :43-9.

4- Baumrind D. The influence of parenting style on adolescent competence And use. J Early Adolesc1991; 11(1): 56-95.

5- De Hart T, Pelham BW, Tennen H. What lies beneath: parenting style and implicit self-esteem. $J$ Exp Soc Psychol2006; 42(1): 1-17.

6- Reitman D, Rhode PC, Hupp SDA, Altobello C. Development and validation of the parental authority questionnaire-revised. $J$ Psychopathol Behav Assess2002; 24(2): 119-27.

7- Sadegh Khani A, Ali Akbari Dehkordi M, Kakujouibari, A. Disorder and mothers of normal students of the same age in Ilam city. Psychology of exceptional individuals2012; 3(6): 95-114.

8- Dwairy M, Menshar KE. Parenting style, individuation, and mental health of Egyptian adolescents. $J$ Adolesc2006; 29(1): 103-17.

9-Kerr DC, Lopez NL, Olson SL, SameroffAJ. Parental discipline and externalizing behavior problems in early childhood: The roles of moral regulation and child gender. J Abnorm Child Psychol2004; 32(4): 369-83. 10- Galambos NL, Barker ET, Almeida DM. Parents do matter: Trajectories of change in externalizing and internalizing problems in early adolescence. Child Dev2003; 74(2): 578 -94.

11- Bugental DB, Grusec JE. Socialization processes. In: Eisenberg N, ed. Social, emotional, and personality development.the Handbook of child psychology (6th ed). Canada, NJ: Wiley \& Sons; 2006. pp: 366-428.

12- Bumrind D. Parental disciplinary patterns and social competence in children. Youth \& Society1978; 9(3); 239-67.

13- Hosseinpoor K. Maternal parenting style's effects on the symptoms of stress, anxiety and depression in children. [Thesis]. School of psychology. Mashhad: University of Mashhad 2004; pp: 38-45.

14- Buri JR. Parental authority questionnaire. J Pers Assess 1991; 57(1): 110-19.

15- Grayson P,Carlson GA. The utility of a DSMIII-R based checklist in screeing childpsychiatryic patients. J Am Acad Child Adolesc Psychiatry1991; 30(4): 669-73.

16- Kalantari M, Neshat Doost H, Zareie MB. The effectiveness of behavioral parent training and medication therapy on the symptoms of attention deficit hyperactivity disorder in children / hyperactivity. Journal of Psychology2000; 5(2,18): 118 -35.

17- Asher A. Exploring the relationship between parenting styles and juvenile delinquency. [Thesis]. Science department of family studies and social work. USA: Miami university 2006.

18- Okorodudu GN. Influence of parenting styles on adolescent delinquency in delta central senatorial district. Edo J Counsel2010; 3(1): 58-86.

19- Lei-Yin C, Xue-Rong L, Zhen W, et al. Parenting styles, parenting locus of control and family function of children with oppositional defiant disorder. $J$ Clin Psychol2011; 10: 2-20. 
20- Farzi Golfazani M, Mohammed Ismail E, Rauofiyan Moghaddam F, Asgari Moghadam H. Comparing maternal parenting with depressive disorder, anxiety and OCD children with mothers of normal children. Research Exceptional Children2004; 9(3-4): 245-64.

21- Karahmadi M, Tabaiean R, Afkhami-Aghda M. Parental interaction patterns in children with Adhd and controls a comparative study. Journal of Shahid Sadoughi
University of Medical Sciences2007; 15(1): 35-43.

22- Kamijani M, Maher F. Comparison of parenting styles with adolescents and juvenile's behavioral disorder with normal cases. Knowledge \& Research in Applied Psychology2009; 9(33): 63-94.

23- Sohrabi F, Hassani A. Parenting style and parental antisocial behavior in adolescent girls. Journal of Psychology2009; 11(1): 75-88.

Copyright(C) 2016 ASP Ins. This open-access article is published under the terms of the Creative Commons Attribution-NonCommercial 4.0 International License which permits Share (copy and redistribute the material in any medium or format) and Adapt (remix, transform, and build upon the material) under the Attribution-NonCommercial terms. 